\title{
Dialectic Unity of the Domestic and Foreign Policy of China On the Centenary of the Communist Party of China
}

\author{
K. M. Barsky ${ }^{a, *}$, A. V. Vinogradov ${ }^{b, * *}$, and A. I. Salitskii ${ }^{c, * * *, \#}$ \\ ${ }^{a}$ Ministry of Foreign Affairs of Russia, Moscow, Russia \\ ${ }^{b}$ Peoples' Friendship University of Russia (RUDN University), Moscow, Russia \\ ${ }^{c}$ Primakov National Institute of the World Economy and International Relations, Russian Academy of Sciences, \\ Moscow, Russia \\ *e-mail: kirill_barsky@yahoo.com \\ **e-mail:vinogradov-a.v@mail.ru \\ ***e-mail:sal.55@mail.ru
}

Received April 5, 2021; revised April 27, 2021; accepted May 5, 2021

\begin{abstract}
This July marks the 100th anniversary of the founding of the Chinese Communist Party. This event motivated the authors of this article to consider the main problems that modern Chinese society is solving, the place of the PRC in the world economy and politics at the beginning of the third decade of the 21st century, and China's growing influence on the planet. China's undoubted successes, including in the fight against the coronavirus pandemic and in overcoming the recession caused by tough quarantine measures in early 2020, show the considerable viability of the state created by the Chinese communists, which is increasingly at the forefront of the world in the economy, science and technology, and culture. However, the path to the current rise of the great power was by no means an easy one, and the prospects for its development are perhaps one of the most debated issues in international discussions. China never tires of emphasizing the specifics of its history. At the same time, the diversity of the internal conditions of the colossal country together with the skillful application of carefully studied foreign experience yielded the extraordinary wealth of forms of development, which can serve as a guarantee of new achievements and, possibly, useful universals for all humankind.
\end{abstract}

Keywords: People's Republic of China, Communist Party of China, development, socialism, economic model, market, self-reliance, independence, diplomacy, policy, Chinese Dream.

DOI: $10.1134 / \mathrm{S} 1019331621040110$

The 100th anniversary of the Communist Party of China (CPC) in 2021 could not go unnoticed. What is the significance of the anniversary? In our opinion, it is precisely in the fact that it symbolizes the end of the era of the crisis of Chinese civilization, which began with the invasion of Western powers and the opium wars of the mid-19th century, evidencing the backwardness of the Chinese society of that time. However, China never put up with defeat; it resisted and tried to overcome backwardness, first by pursuing a policy of "self-strengthening," then by the reforms of Kang Yuwei (late 19th century). Finally, in 1911, the Xinhai Revolution broke out, and there arose the idea of

\footnotetext{
\# Kirill Mikhailovich Barsky, Cand. Sci. (Hist.), is Senior Official of Russia for APEC and Ambassador-at-Large of the Ministry of Foreign Affairs of the Russian Federation. Andrei Vladimirovich Vinogradov, Dr. Sci. (Polit.), is an RUDN Professor and a Sector Head at the RAS Institute of Oriental Studies. Aleksandr Igorevich Salitskii, Dr. Sci. (Econ.), is Chief Researcher of the Primakov Institute of World Economy and International Relations, RAS (IMEMO).
}

a republic of "three principles of the people" of Sun Yat-sen, which has never been implemented to the full. The country, a victim of internal strife and the inertia of backwardness and greed of the colonial policy of the world powers, continued to collapse.

The shots of the Aurora, according to Mao Zedong, brought to China the universal truth of Marxism-Leninism. A positive symbol of the emerging era was the appearance of the first Chinese Marxists and the Communist Party, which defeated its political opponents and won power in the country in 1949. The unity of the state was restored, and the ancient civilization witnessed the beginning of the construction of a new life. However, China did not find its path of development at once.

In the 1950s-1970s, under the guidance of the Communist Party, the PRC leadership looked over possible development options, studied, sought, and made mistakes, sometimes with dire, dramatic consequences, but the country stubbornly moved forward. 
The mistakes were corrected. In the last quarter of the 20th century, China finally modernized, built a socialist market economy and "socialism with Chinese characteristics," reconciling tradition and modernity. By combining its advantages with the achievements of the outside world, the PRC used the challenge from the West as an opportunity for development. However, the significance of the 100th anniversary of the Chinese Communist Party is not exhausted by successes in overcoming the crisis. Against the background of the historical rise of China, humanity, especially its western part, is rapidly sinking into the abyss of a deep civilizational crisis. Everything indicates that a change of milestones and leaders has begun. From the periphery of history, China is moving to the forefront, to leading roles, looking for promising ways of development for all humankind.

\section{THE POLITICAL ECONOMY OF CHINESE SOCIALISM}

In the late 1970s, after major defeats in Mao Zedong's experiments, the CPC found itself at a crossroads. A complete rejection of the legacy of the "Great Helmsman" could lead to a rejection of socialism and, hence, the power of the Communist Party. On the other hand, the successes of the socialist transformations of the first half of the 1950s were still fresh in the people's memory. During heated internal party discussions, some members of the leadership expressed the opinion that China was not yet ready for socialism, that it needed a step back to return to the presocialist stage. However, doubts about the socialist choice were rejected, it was decided to preserve the socialist character of development and recognize the historical merits of Mao Zedong, while all the shortcomings and inconsistencies with classical ideas were explained by the specifics and complexity of the initial stage of socialism. A distinctive feature of the new course was the shift of the center of gravity to economic construction.

In 1982, the general course towards the preservation of socialism was consolidated in the official formulation of socialism with Chinese characteristics. Its theoretical ambiguity left wide scope for both practical action and theoretical interpretation, which determined the CPC's pragmatic, flexible, and probably therefore effective course.

Shortly before the presentation at the 13th CPC Congress (1987) of the concept of "the initial stage of socialism," linking the socioeconomic and political aspects of development, Deng Xiaoping, who at that time no longer held key posts in the party but remained the ideological leader, suggested that only in the mid-21st century, upon reaching the level of middle-developed countries, would China be able to declare socialism built and speak out loudly about the superiority of socialism over capitalism [1, p. 309]. It seems that today's Chinese society has grown to this level in many respects, and although the CPC documents still refer to the "initial stage," the country's leaders speak and write increasingly often about the advantages of socialism in its Chinese version. Moreover, in the mid-2010s, high assessments of the political system of China began to appear in the West as well [2, pp. 185-198].

Note that the concept of the initial stage of socialism was a major theoretical contribution of the CPC to Marxist theory and even its correction: in fact, socialism was recognized as a separate formation and not just a transitional period between capitalism and communism, as in Marxism [3, pp. 172-178]. This formulation of the question justified, first, the CPC's long stay in power and the need to preserve a strong state (which in classical Marxism, when approaching communism, is supposed to wither away). Second, it became possible to set relatively modest tasks for the country, not to rush forward at any cost in the historical competition with capitalism, which had discovered internal reserves of development, and the main imperialist power. Finally, third, the concept of the initial stage opened space for experiments, choice based on the usefulness of a variety of development tools, and convergence of theory and the needs of practice-as a rule, not at the expense of practice for the sake of ideological purity, as was often the case in the Soviet Union, but due to the rejection of some unreplaceable theoretical positions, which, in turn, predetermined the reliance on experiment and pragmatism.

From practice, gradually, with discussion and struggle, theoretical postulates grew and were confirmed in the strategy: "commodity economy"; "socialist market economy"; the idea of "Three Represents"; and even "harmonious society," which challenged the class struggle as the main source of development and possible in classical Marxism only at the highest, communist stage.

The practical effect of all these theoretical innovations was undeniable. Already in the formula socialist market economy, adopted by the 14th CPC Congress (1992) after Deng Xiaoping's landmark trip to the south of the country at the beginning of that year, the contradiction between market and planning was resolved: they were recognized as equal complementary elements; ${ }^{1}$ the bright formula "the market directs the enterprises, the state directs the market" was also coined. An economic boom began in China.

A decade later, at the 16th CPC Congress (2002), private capital was recognized as a full-fledged participant in socialist construction; its new status was fixed in the Constitution. By that time, the country had

\footnotetext{
${ }^{1}$ The scientific literature often puts forward the thesis that since China is oriented towards the market, it means that this is not socialism but capitalism. However, the market also existed in the formations preceding capitalism; moreover, F. Braudel notes that historically, in the 16th-18th centuries, it was big business that oppressed and destroyed the market.
} 
Table 1. Growth in GDP, investment, and labor productivity in the PRC, 2016-2020, \%

\begin{tabular}{l|c|c|c|c|c}
\multicolumn{1}{c|}{ Indicators } & 2016 & 2017 & 2018 & 2019 & 2020 \\
\hline GDP & 6.7 & 6.8 & 6.6 & 6.0 & 2.3 \\
\hline Investment in fixed assets & 7.9 & 7.0 & 5.9 & 5.1 & 2.7 \\
\hline Labor productivity & 6.4 & 6.7 & 6.6 & 6.2 & 2.5 \\
\hline
\end{tabular}

Source: data of the National Bureau of Statistics of China.

already launched a grandiose infrastructure construction; its own TNCs were being formed, the country entered the WTO, and the export sector was rapidly progressing. Competition was developing, science and technology were coming to the fore, and consumer and environmental revolutions started. At the same time, new contradictions arose: between labor and capital, national and foreign entrepreneurs, the center and the provinces. The state actively participated in the development process, preventing contradictions from escalating into destructive, antagonistic conflicts.

Issues of acute property stratification, corruption, and environmental and raw materials crisis were openly discussed during that period. The "New Left" appeared-influential intellectuals and party workers reacting to acute social conflicts and imbalances, which had already arisen within the framework of economically successful socialism. In the mid-2000s, the CPC began "reforming reforms," focusing on the problems of social justice and the struggle against liberal ideology, perceived as a challenge to the political stability of the PRC [4].

The most striking evidence of the adjustment of the course towards economic growth at any cost was the increased responsiveness of the Chinese state to the problems and demands of the population [5, p. 194], which was primarily embodied in the creation of a modern social security system, including in the countryside (free medical care, secondary education, pensions, etc.), which had been practically absent in any developed form throughout the entire period starting from the formation of the PRC. The crisis of 2008-2009 somewhat slowed down the planned transformations in the social sphere. An even more radical shift in the development model of the PRC took place after the coming to power of the new leadership headed by Xi Jinping. The 3rd Plenum of the 18th CPC Central Committee (2013) was decisive. The economic strategy oriented towards exports and investment in infrastructure was gradually replaced by development based on scientific and technological progress and domestic demand. It is no longer the pace of progress that comes to the fore but the desire to establish a socially oriented society, merciless to vices such as poverty and corruption, which they begin to fight not only systematically but also with tangible results. Thus, in practice, China returns to the ideas of social justice, closing the cycle "economic growth-socioeconomic development-problems and contradictions-social justice" at a new stage of development.

China has developed an original model of positive development through solving the problems of backwardness, and this is the most important task of socialism. Having done it on its own and not according to Western models, it immediately moved to another category, to the major historical league. This is a Renaissance in the full sense of the word. For civilization, the preservation of historical subjectivity is no less important than the economic successes that have been demonstrated by many countries of East Asia, but none of them claims a special path of development. China is parting with the past, with the "century of humiliation," and regaining its role as a leading power in Asia. However, there is a need for an image of the future, which was outlined by the new leader of China in the form of the "Chinese Dream" (2012).

The first five-year period after Xi Jinping's coming to power (2016-2020) was planned as a period of intensification of economic development, reduction of excess production capacity, and a more moderate growth in investment in the national economy, which in 2012-2013 had been about 20\% per year. China managed to cope with these tasks; the economy improved and successfully passed the difficult tests of the 2020 crisis (Table 1). In fact, the development model is changing: from extensive, investment-based growth, China is moving to a knowledge-intensive, hightech digital economy, which opened a new page in the history of human civilization during this period. Two milestones have coincided in the development of humankind and in the development of China. Such synchronization gives an advantage, a multiplier effect: the country does not need to overcome internal inertia; it immediately finds itself at the forefront of world development.

Of course, China has not caught up with the most developed countries in terms of per capita income, but it is ready to join the race for leadership in the new era, to remain as a historical actor; it has not rolled to the sidelines of history, which seemed quite likely 30 years ago. It has managed to solve the main task-to remain as a special civilization, taking its place among the mightiest powers of our time.

In the last decade, the social orientation of state policy has noticeably increased. It is symbolic that 
shortly after the October 2020 Plenum of the Central Committee of the Communist Party of China, the Qiushi (Seeking Truth) journal first published Xi Jinping's speech at the Politburo collective training in 2015, which emphasized the urgency of reducing the gap in welfare between individual population groups, the importance of redistribution, the identification of the advantages of the socialist market economy, and the overcoming of defects of the capitalist economy [6]. Note that against the background of stagnation of labor incomes in Western countries over the past decade, remunerations in China have increased rapidly, and labor productivity keeps up with it, growing in the 2010 s by an average of $7-8 \%$ per year against $1 \%$ in the United States [7, pp. 58-61].

The CPC has consistently recruited entrepreneurs into socialism. During the entire 13th five-year period (2016-2020), a policy was pursued to simplify the activities of small and medium-sized businesses, ridding them of obsolete bureaucratic regulations. In 2020, against the backdrop of the pandemic, small businesses were provided with significant benefits and indulgences, which will remain in 2021. It is noteworthy that after overcoming the crisis caused by the pandemic, Beijing intensified its antimonopoly policy: the March 2021 session of the National People's Congress of China (NPC) instructed its Standing Committee to finalize the relevant legislation and fill in the gaps in the regulation of the digital economy.

China purposefully is seeking to fit into the general trends of postindustrial development and has formed the respective subject fields and a development agenda that includes all the latest trends-informatization, digitalization, environmental protection, green economy, and the use of artificial intelligence and big data, including in the regulation of social processes and relationships. The CPC and the government are consistently pursuing a policy of protecting small and medium-sized businesses from the oppression of monopolies, both domestic and foreign. The sensational stories with Alibaba and Tesla in late 2020-early 2021, when the regulator took measures to restrict their activities in the interests of other market participants, are indicative. The development of legislation has begun to prevent the dictates of digital giants.

This contrasts with the increasing oppression of the market by monopolies in Western countries [8, 9]. Foreign researchers agree that one of the causes of the current decline of the West is the activity of large and superlarge TNCs, which have taken over governments, other branches of power, and many international and nongovernmental organizations. As a result, the market space is gradually narrowing, employment is reduced due to the suppression of small business, and the state fails to fulfill its regulatory functions.

Modern China is characterized by a combination of market and government regulation, maintaining a balance between them. The PRC manages to avoid the dictatorship of either the state or capital, which is no less destructive than the antagonism of classes, labor, and capital. The all-pervading party has managed to subordinate and involve big business, including private and foreign, in solving national strategic problems, be it the development of backward regions, the assimilation of foreign sources of fuel and raw materials, or environmental and technological plans. Foreign researchers consider the vigilance of the country's central bank, limiting the international movement of financial capital, to be an important condition for the integrity of China's political and economic system [7, p. 47].

The decisive role of the state is especially clearly visible in new, breakthrough technologies and hightech sectors of the economy. A major task of the 14th five-year plan (2021-2025) in China is to strengthen the self-sufficiency of the economy and its technological independence. The report of the Minister of Finance to the NPC session in 2021 provides for an increase in funding for basic science by $10.6 \%$ with an increase in budget expenditures in general by $1.8 \%$. The social orientation of the current course in the field of science and education is clearly manifested in the tendency towards the "noncommercial nature of education and developmental education for a greater number of talents who can contribute to the country's qualitative development and a high level of self-sufficiency" [10, 11, p. 653].

Tense relations with the Western world make topical the development of science and technology in China. In these conditions, the decisive role again belongs to the state, which is developing the appropriate policy. After all, technological independence is the ability to respond to the challenges of the time, a prerequisite for the establishment of something new in the economy and society, it is a matter of ensuring national security. Advanced technologies have been playing a significant role in the Chinese renaissance, in reducing dependence on the outside world, and in maintaining critical links of the economic system (NPPs, ecology, banks, etc.). The state also ensures digital sovereignty.

Faced with protectionism, deglobalization, and technological warfare in foreign markets, China is shifting the center of development to the domestic market or, as indicated in the 2020 CPC documents, the "internal contour," which should now also guarantee the generation of new technologies. Expanding sales within the country at the expense of income growth for the less well-off strata of the population is seen as a fully achievable goal. It is illustrated by the standard example of income distribution between two market participants: with an income ratio of $2: 8$, only one participant will buy a product at a price of three units, but if the income is distributed in a $4: 6$ ratio, then there will already be two such buyers. There is the well-known experience of successful growth policies 
with an emphasis on enhancing equality in the United States in the 1950s and 1960s and in Taiwan in the 1970s.

The socialist market is an important tool to achieve the Chinese Dream. Having solved the most difficult problems of life support for a huge country with a growing population, the CPC can now safely rely on the "living creativity of the masses," protecting it from oppression by monopolists and bureaucrats and encouraging collective self-organization, cooperation, mutual assistance, and even crafty circumvention of strict regulations. The people's initiative can rely on highly developed hard and soft infrastructure. This is how the Chinese Dream is gradually acquiring the contours of not a bureaucratic state but people's socialism. From an arrogant bureaucrat, the state turns into an organizer of people's life.

Today we are witnessing a sufficiently mature construction of socialism in China, or a system that can reproduce itself. At the beginning of the third decade of the 21st century, it is quite right to talk about the completion of the initial stage, about the establishment of a stable, systemically complete socialism in China. In other words, we see a mature, established socialism, which continues to develop. This system is still far from the classical ideals of European socialism, including social equality. Yet the approach to them, especially in the past decade, has definitely been outlined. This is also confirmed by independent data on the growing popularity of the Chinese leadership within the country [12].

Turning to the international aspects of the "two contours" of the economy, indicated in the party documents, i.e., internal (main) and external, let us note that back in the early 2010s China threw down a confident challenge to Western domination [13, p. 42], a challenge that now contains a convincing socioeconomic component. Thus, we are talking about a new quality of global confrontation: in contrast to crises and decline, Beijing has proposed an attractive alternative model, in which the "sacred right to development" is central [14].

\section{DIPLOMACY AS A FACTOR OF SUCCESS OF CHINESE SOCIALISM}

At the finish line of a 100-year-long marathon, the century-long path of the Chinese Communist Party, one can state that the judges will fix not only an undeniable victory but also a world record. Chinese diplomacy has contributed much to this phenomenal result.

The offensive character of Chinese diplomacy was laid as early as at the stage when the young Chinese Communist Party was just unfolding a revolutionary struggle for power and formulating its goals, including in international relations. The ability to defend its interests firmly was subsequently manifested many times at different stages of China's foreign-policy activity.

The CPC's position on international issues was originally purely ideological, painted in black and white. The picture of the world was formed under the influence of the Soviet Bolshevik Party and the Comintern, and the tasks largely coincided with the tasks of the world communist movement. Over time, the CPC leadership began to specify China's approaches in foreign policy with account for national interests.

Even before the victory of the people's revolution, Mao Zedong got his first impressions of his communication with American diplomats, who, at the final stage of the anti-Japanese war (1944-1945), probed the sentiments and proposed themselves as mediators between the CPC and the Kuomintang. The first experience of negotiations was the participation of the delegation of communists led by Zhou Enlai in the preparation and conduct of the Political Consultative Conference in Chongqing in 1945-1946.

The victory in the civil war and the formation of the People's Republic of China became a fundamental watershed: the communists perceived themselves as the heirs of Chinese statehood, which could not but lead the CPC leadership to rethinking its functions and making goal setting in the field of foreign policy more complicated. Beijing began to act simultaneously as a part of world socialism, opposing world imperialism, and in the role of a national state, expressing the interests of the Chinese nation and the entire great civilization [15, pp. 110-125].

Just like the Soviet Communist Party, the ruling parties of other socialist countries, and other communist and many workers' parties, the CPC proclaimed the victory of socialism over capitalism as its ultimate goal. At the same time, Chinese diplomacy, already in the first years of the existence of the PRC, was faced with the need to ensure favorable external conditions for the internal development of China and to negotiate with foreign representatives, not only Soviet ones.

The history of the PRC's foreign policy shows that the traditional political culture of China has always had a colossal influence on Chinese diplomacy. In the first place, this includes striving for order and harmony; the perception of the world as a hierarchically ordered macrocosm; reverence for the wisdom of philosophical theories; the preference for diplomatic methods as opposed to military decisions; strategic thinking; practicality as part of national psychology; and the habit of thinking over everything carefully, planning, calculating, and being prudent in actions. Add to this the ancient Chinese foreign policy concepts, recorded in the historical annals, and the vicissitudes of China's relations with neighboring states and distant powers, kept in historical memory [16]. In this sense, at the dawn of its formation and at the early stages, the foreign policy of the PRC experienced seri- 
ous overloads. It took a long time before Chinese diplomacy found its face.

Note that in matters of organizing the diplomatic service, the young republic made a colossal step forward in comparison with the diplomacy of old China. The Soviet Union played a significant role in its buildup-from diplomatic recognition immediately after the formation of the PRC and support for the first steps of Chinese diplomacy in the international arena to practical assistance in training. However, it was a purely national diplomatic service, which, along with revolutionary novelty, absorbed much from the arsenal of traditional Chinese diplomacy. As it was said figuratively in ancient China, "Blue comes from indigo and is bluer than the indigo." This was the case.

At the initial stage, the foreign policy of the PRC was formulated and directed by Mao Zedong personally. Yet it was State Council Premier and First Foreign Minister Zhou Enlai who directly supervised the foreign-policy activities. It was he who played the key role in the shaping of the Chinese diplomatic school and in the development of the principles, theory, and practice of the diplomacy of People's China. "Zhou Enlai's diplomacy" was distinguished by a combination of firmness in upholding national interests and a search for balance in building relations between the PRC and foreign countries [17, pp. 96-118].

Even though China's foreign policy in the first three decades of the existence of the PRC was contradictory, achievements were also evident. These include the approval of an independent course; the development in the 1950s of close cooperation with the Soviet Union and the countries of the socialist camp; participation in the development of five principles of peaceful coexistence; participation in the Bandung (Asian-African) Conference (April 1955), the final document of which formulated the "Ten Principles of Bandung"; strengthening the authority of the PRC in the eyes of developing countries; the return of China to the United Nations on October 25, 1971; the visit to the PRC of US President R. Nixon in February 1972 and the normalization of Sino-American relations; establishment of diplomatic relations with Japan and Britain (1972); formulation of the Chinese position on the Taiwan issue; and elaboration and development of the concept of "people's diplomacy."

It is noteworthy that the Sino-American negotiations at the end of the Korean War in Panmunjom, Geneva, and Warsaw contributed to the elaboration of a special style of Chinese diplomacy. Even then, it was distinguished by a firm and competent defense of China's interests along with the readiness to make compromises, the ability to enter sharp polemics and make unexpected moves, the ability to hide its own weaknesses and make the most of limited advantages, the attitude to negotiations as a way to convince the opposite side of the moral and factual rightness of the Chinese position, and the perception of the negotia- tion process as a permanent bargaining. In addition, Chinese diplomats learned how to use the rich arsenal of various diplomatic techniques [18, pp. 50-63].

The era of the 1950s-1970s was a time when a whole galaxy of brilliant diplomats came to the fore. These were Wang Bingnan, Han Nianlong, Qiao Guanhua, Qian Qichen, and others, whose names are forever inscribed in the history of international relations. In the 1970s and 1980s, China managed to turn the dark page of the so-called "Red Guard" diplomacy during the "Cultural Revolution," which affected not only China's relations with many foreign states but also employees of the Foreign Ministry and Chinese diplomacy in general. China paid a dear price for that mayhem.

The period of diplomacy by Mao Zedong-Zhou Enlai was an exceptionally important stage in the transformation of traditional methods of foreign policy into modern ones. It was a time of unprecedented foreign-policy creativity, including the development of radically new concepts and the testing of new approaches. The new diplomacy emerged under an extremely strong ideological influence in very hard conditions of the development of the socialist system and acute struggle in the international arena. Without that diplomacy, sometimes successful, sometimes erroneous, often contradictory, there would be no diplomacy of today's China. One of the dramatic excesses of that period was the cooling of relations and then the confrontation between two former allies-the PRC and the Soviet Union. True, here too, diplomacy played a positive role-first in keeping the parties from a full-scale armed conflict and then, after the historic meeting of A.N. Kosygin with Zhou Enlai at the Beijing airport in September 1969, also in bringing the Soviet-Chinese relations to the trajectory of movement towards the restoration of what had been lost [19].

In the early 1980s, the strategic costs of the "united front" course of struggle against Soviet hegemony, which had been pursued for a decade and a half, began to be obvious. Gradually, Beijing understood that the line towards a lop-sided partnership with the West and a further deterioration in relations with the Soviet Union could guarantee neither a truly independent foreign policy nor the implementation of the reform policy in the interests of China's modernization, proclaimed by the country's new leader Deng Xiaoping. The main tasks of the PRC became the acceleration of socialist modernization and the struggle for the unification of the Motherland and for the preservation of peace in the world. Characteristically, all these tasks were somehow connected with the implementation of the country's foreign policy and foreign economic course.

With the beginning of the reforms, the top leadership of the CPC and the PRC, which were gradually revising their views on relations with foreign countries, 
latently made a cardinal change in foreign-policy ideology. Specific foreign-policy guidelines were brought in line with the tasks of economic reforms and openness, and foreign policy was put at the service of the country's modernization. As a result, it became possible to develop a new paradigm for China's existence in the surrounding world and communication with it.

Having abandoned the "revolutionary diplomacy" of the previous period, the Chinese reformers embarked on the path of developing friendly relations with foreign countries, China's constructive participation in world affairs, and gradual integration into the system of international relations [20]. This road was not smooth. The decisive actions of the CPC leadership, headed by Deng Xiaoping, in response to the events in Tiananmen Square in June 1989 resulted in anti-Chinese sanctions on the part of the United States, Western Europe, and Japan, which tried to organize the international isolation of China. The Chinese managed to overcome the acute crisis in foreign policy primarily thanks to a wise domestic policy, which first ensured political and economic stabilization in the country, and after a while the continuation and acceleration of the policy of reforms and openness. An important role in countering sanctions was played by Beijing's active foreign-policy efforts, using its reserves of relations with friendly countries, supporting the anti-Iraqi coalition during the Gulf War, and ingenious tactics in other international affairs. A great help for China was the moral and political support of the Soviet Union, with which the PRC normalized relations in May 1989; at the same time, interparty relations between the CPC and the CPSU were restored [21].

Having painfully endured the disintegration of the Soviet Union and the collapse of socialism in Eastern Europe, China refrained from starting a new ideological polemic and took a course towards establishing normal relations with all the countries of the former "Eastern bloc," primarily with Russia. Beijing's active policy towards the CIS countries contributed to the establishment of good-neighborly relations with them, blocked the Taiwanese diplomatic offensive, and prepared the next stage-the stage of expanding the Chinese presence in the post-Soviet space, primarily in Central Asia.

The example of the acute international reaction to the Tiananmen events demonstrated to China the priority of maintaining equal relations with the leading Western countries and at the same time destroyed the last illusions about the real motives of the US Chinese policy. Beijing made an important conclusion for itself about the need for a multivector foreign policy, within which efforts to establish stable mutually beneficial ties with Western countries would be combined with the development of closer cooperation with Russia, other neighbors, regional states, and developing countries.

HERALD OF THE RUSSIAN ACADEMY OF SCIENCES
Deng Xiaoping's reforms and the efforts of his followers-General Secretaries of the CPC Central Committee Jiang Zemin and $\mathrm{Hu}$ Jintao-led to an unprecedented rise of China and the strengthening of its overall power and the position of the PRC in the international arena. However, this scared the West. In those circumstances, China required particularly careful diplomacy. Apparently, this determined the diplomatic strategy that Deng Xiaoping formulated in 28 characters in the early 1990s. In his opinion, over a long period of time, China should adhere to the following principles in the international arena: to be able to observe in cold blood; to strengthen shaky positions, showing endurance; to learn how to cope with difficulties; to keep in the shadows, trying not to show itself in any way; to be able to defend, albeit awkward, its own approaches; never to claim leadership; and to play its role by doing what is currently possible. These commandments predetermined the model of China's foreign policy behavior for the next two decades, honing the qualities of Chinese diplomacy, such as strategic patience [22, pp. 9-27].

The 1990s saw an explosive expansion of the range of forms and methods of Chinese diplomacy and its geographical and functional coverage. This new trend was the result of the orientation towards the internal needs of China, a reflection of the peculiarities of the development of the modern world. Only a very competent and flexible diplomacy, guided by a well-considered strategy but ready to sacrifice much for tactical purposes, to the point of giving up what seemed unshakable, could ensure such compliance.

The key to solving diplomatic problems in the changing environment was constant self-reform, continuous analysis of the situation, and firmness in defending the country's positions along with the ability to make bold, unorthodox decisions. By changing, China and its diplomacy not only managed to stay on the crest of the wave of global trends but also, having adapted to them, began to a certain extent to manage the developing globalization and the emerging aspirations of the Asia-Pacific countries for regional cooperation.

In some issues, there was a return to the policies of the early 1950s (five principles of peaceful coexistence, self-reliance), while in others, there was an appeal to even deeper, fundamental foundations, i.e., to traditional values and basic concepts such as harmony, order, respect, and balance of interests. In the PRC's foreign policy, peace and good neighborliness again became the most important guidelines. It is no coincidence that since the late 1980s China has been actively involved in multilateral diplomacy. In less than ten years, the PRC itself began to participate in the creation of new multilateral organizations and fora, among which the SCO and BRICS occupy a special place.

Vol. $91 \quad$ No. $4 \quad 2021$ 
In an extremely short time, Chinese diplomacy learned to use the tools of "soft power," many of which, as well as the very concept of J. Nye, were perceived in China as the development of the teachings of Chinese sages and the improvement of the diplomatic practice of the dynasties of the past. A Taoist maxim says, "The soft overcomes the hard." Network diplomacy, cultural diplomacy, public diplomacy, information diplomacy, and digital diplomacy today serve as a weighty toolkit of the PRC's foreign policy [23]. China has made significant progress in applying the methods of economic diplomacy. Its quintessence is the Belt and Road Initiative.

The pandemic of the new coronavirus infection has provoked the emergence of "mask" and "vaccine" diplomacy. The announcement of a trade war to China by the Americans, the proclamation by the West of a course of comprehensive containment of the PRC, and the aggravation of the geopolitical situation gave rise to new forms of foreign-policy struggle such as discursive diplomacy and "wolf warrior diplomacy," i.e., the harsh and uncompromising rhetoric of Chinese officials. China, which has always opposed unilateral sanctions against other states, was forced to adopt certain elements of the sanctions policy.

All these types of diplomacy, relying on the country's economic, scientific, technical, cultural, defense, and information potential, which has grown immeasurably compared to recent times, are unfolding before our eyes and merging into an extensive, multilateral system of development and implementation of a foreignpolicy strategy, supported by think tanks and qualified personnel, closely linked to the development strategy of the country as a whole. It is quite adequate to the challenges and demands of our time.

Note that the independent character of the PRC's foreign policy remains unchanged. The fundamental principles of Chinese foreign policy, such as equality and mutual respect, have not undergone any changes either. Alas, they do not correspond to the current US policy towards China. Hence, the demands on Washington to abandon attempts to talk to Beijing from a position of strength. At the same time, the Chinese leadership remains focused on building equal dialogue and mutually beneficial cooperation with America, as well as with all other countries, and strives to avoid conflicts and confrontation as much as possible. The principle of "the need to seek common ground while reserving differences," formulated by Zhou Enlai, remains in force.

\section{$* * *$}

At the junction of the second and third decades of this century, one can clearly see the organic conjugation of China's domestic and foreign policies and their mutual enrichment and mutual support. This is by no means a conflict-free interaction; it requires that the management system carefully monitor ongoing processes, processing gigantic amounts of information, clearly specialized departments and services, coordination of their activities, a clear hierarchy of goals when making decisions, and account for various interests. It is clear that the preparation of decisions is accompanied by discussions, sometimes heated, but the Chinese try not to advertise them, sparing no effort in consultations and coordination. As a result, verified decisions and plans are consistently implemented, which favorably distinguishes them from impulsive and often disorderly decision making in many other countries.

The growing unity of China's domestic and foreign policies completes the large-scale project carried out by the CPC to build a society that is socialist in its essence. Its impact on the world around it is increasing, opening a new theoretical space for other states to analyze their own experience, possible adjustments to policies and strategies, including in relations with Western countries, TNCs, and international organizations. The consistency and rationality of the Chinese strategy make the PRC a responsible and predictable partner; therefore, practical cooperation with China promises great benefits in an increasingly wider range of areas.

The center of gravity around which China's domestic and foreign policy is now built is undoubtedly the process of development in the fullness of its discoveries and achievements, contradictions and backward movements, and an endless variety of forms. This is a solid foundation for new historic victories and successes in the international arena.

\section{REFERENCES}

1. E. P. Pivovarova, Socialism with Chinese Specifics (ID FORUM, Moscow, 2011) [in Russian].

2. D. A. Bell, The China Model: Political Meritocracy and the Limits of Democracy (Princeton Univ. Press, Princeton, NJ, 2016).

3. A. V. Vinogradov and A. I. Salitskii, "Can we talk about the formation of a new social system in China?," Herald Russ. Acad. Sci. 89 (1), 78-83 (2019).

4. O. N. Borokh and A. V. Lomanov, Hu Jintao's neosocialism and the modern ideology of the PRC. http://polit.ru/article/2006/04/20/boroh/. Cited April 15, 2021.

5. A. N. Korolev, "The PRC political regime's response to the basic needs of the population," Probl. Dal. Vostok., No. 2, 90-107 (2015).

6. Xi Jinping, "Opening up new frontiers for Marxist political economy in contemporary China," Qiushi J. Chinese ed., No. 16 (2020). http://en.qstheory.cn/2020-11/08/c 560906.htm. Cited March 8, 2021.

7. V. K. Fouskas, S. Roy-Mukherjee, Q. Huang, and E. Udeogu, China \& the USA: Globalization and the Decline of America's Supremacy (Palgrave Macmillan, London, 2020). 
8. J. Tepper and D. Hearn, The Myth of Capitalism: Monopolies and the Death of Competition (Wiley, Hoboken, NJ, 2018).

9. T. Philippon, The Great Reversal: How America Gave Up on Free Markets (Belknap Press: An Imprint of Harvard Univ. Press, Cambridge, Mass., 2019).

10. Xi Focus: Xi demands building quality, balanced basic public education service system. http://www.xinhuanet.com/english/2021-03/06/c_139789921.htm. Cited March 12, 2021.

11. T. L. Guruleva and Wang Bing, "Higher education in the PRC: Institutions and mechanisms of state and party governance," Vestn. Ross. Univ. Druzh. Nar., Ser.: Sotsiol., No. 3, 636-654 (2020).

12. E. Cunningham, T. Saich, and J. Turiel, Understanding CCP resilience: Surveying Chinese public opinion through time. Harvard Kennedy School. Center for Democratic Governance and Innovation. July 2020. https://ash.harvard.edu/files/ash/files/final_policy_brief_7.6.2020.pdf. Cited March 9, 2021.

13. K. M. Barskii and A. I. Salitskii, "Polycentrism of the modern world and new bipolarity as a possible scenario of global development," Mir Polit., No. 7, 28-43 (2012).

14. Six points China has to let US understand: Global Times editorial of March 18, 2021. https://www.global- times.cn/page/202103/1218831.shtml. Cited March 20, 2021.

15. H. Kissinger, On China (Allan Lane, London, 2011).

16. L. Pye, The Mandarin and the Cadre: China's Political Culture (Center for Chinese Stud., Univ. of Michigan, Ann Arbor, Mich., 1988).

17. P. J. Fang and L. G. Fang, Zhou Enlai: A Profile (Foreign Languages Press, Beijing, 1986).

18. A. Wilhelm, Jr., Chinese at the Negotiating Table (National Defense Univ. Press, Washington, DC, 1994).

19. M. S. Kapitsa, On Different Parallels: Notes of a Diplomat (Kniga i Biznes, Moscow, 1996) [in Russian].

20. V. A. Korsun, The PRC Foreign Policy in the 80s (Modern Foreign Policy Mechanism of China) (MGIMO, Moscow, 1990) [in Russian].

21. Qian Qichen, Ten Episodes in China's Diplomacy (HarperCollins, New York, 2006).

22. V. Ya. Portyakov, Foreign Policy of the People's Republic of China in the 21st Century (IDVRAN, Moscow, 2015) [in Russian].

23. J. Kurlantzick, China's Charm: Implications of Chinese Soft Power (Carnegie Endowment for International Peace, Washington, DC, 2006). https://carnegieendowment.org/files/PB_47_FINAL.pdf.

Translated by B. Alekseev 